\title{
CONTROLE DO DESPERDÍCIO DE ALIMENTOS EM UNIDADES DE ALIMENTAÇÃO ENUTRIÇÃO
}

\author{
Daniele Carolina da Silva \\ Edivane Maria do Nascimento \\ Iza Vanêssa do Nascimento Da Silva \\ Angell Ângelo Mendes de Almeida ${ }^{1}$ \\ Diogenes José Gusmão Coutinho²
}

\begin{abstract}
RESUMO: O desperdício de alimentos está relacionado ao preparo de alimentos em UAN quando as sobras dos alimentos produzidos não são distribuídas, bem como quando os restos de alimentos não consumidos são deixados nos pratos dos clientes. Destaca-se que as UAN's precisem estabelecer o nível de desperdício de alimentos entre o e $10 \%$. O estudo tem como objetivo identificar os fatores associados ao desperdício de alimentos em Unidade de Alimentação Nutrição. Trata-se de um estudo do tipo revisão integrativa da literatura, sendo o levantamentobibliográfico realizado nas bibliotecas eletrônicas SciELO e BVS com as seguintes bases de dados: LILACS e MEDLINE, disponibilizados diretamente por intermédio de pesquisa online. O gerenciamento e controle do desperdício de alimentos em uma UAN, é fundamental para identificar o acúmulo de restos e sobras, acarretando em repercussões ética e econômica, bem como política, social e ambiental. Registrar a quantidade desprezada é muito importante em uma UAN, uma vez que esses dados podem ser utilizados para implementarem estratégias de racionar, visando minimizar os desperdícios e otimizar a produtividade. Além disso, os registrosfornecem informações acerca da quantidade de alimentos perdidos, sendo utilizados no cálculo dessas perdas, bem como mensurar os custos e diagnosticar as causas do desperdício. Frente aoexposto, observa-se que os responsáveis pela UAN devem implantar medidas educativas aos comensais assim como para os funcionários, aonde é fundamental que haja a aplicação de treinamentos para que os mesmos estejam aptos a utilizar os utensílios adequados e treinados para distribuição e padronizando a porção dos alimentos, o que promove a redução dodesperdício.
\end{abstract}

Palavras-chave: Desperdício de Alimentos. Alimentação Coletiva. Aproveitamento Integral Dos Alimentos. Nutricionistas.

ABSTRACT: Food waste is related to food preparation in UAN when the leftovers of the food produced are not distributed, as well as when the remains of uneaten food are left on customers' plates. It is emphasized that the UAN's need to establish the level of food waste between o and ro\%. The study aims to identify the factors associated with food waste in a Nutrition Food Unit. This is an integrative literature review study, and the bibliographic survey was carried out in the electronic libraries SciELO and BVS with the following databases: LILACS and MEDLINE, made available directly through online research. The management and control of food waste in a UAN is essential to identify the accumulation of leftovers and leftovers, leading to ethical and economic repercussions, as well as political, social and environmental. Recording the amount wasted is very important in a UAN,

\footnotetext{
${ }^{\mathrm{I}}$ Mestre. Professor e orientadador.

${ }^{2}$ Professor e orientador. Doutor em Biologia Vegetal da UFPE. E-mail: gusmao.diogenes@gmail.com
} 
since this data can be used to implement rationing strategies, aiming to minimize waste and optimize productivity. In addition, the records provide information about the amount of food wasted, being used in the calculation of these losses, as well as measuring the costs and diagnosing the causes of waste. Given the above, it is observed that those responsible for the UAN should implement educational measures to the diners as well as for the employees, where it is essential that there is the application of training so that they are able to use the proper utensils and trained for distribution and standardizing the portionof food, which promotes waste reduction.

Keywords: Food Waste. Collective Feeding. Food Utilization. Nutritionists.

\section{INTRODUÇÃO}

A produção de refeições quando feitas para o coletivo, é realizada em espaços destinados para essa finalidade e que denominam-se como Unidade de Alimentação e Nutrição (UAN), que se trata do ambiente utilizado para fornecimento de refeições fora da residência. Além disso, uma UAN é local destinado para o preparo e manipulação adequada dos alimentos que dependem de execução de sistemas operacionais padronizados claros e precisos, visando de fornecer alimentos seguros para manter ou recuperar a saúde para quem utiliza de seu serviço (VIANA; FERREIRA, 2017).

De acordo uma publicação da Associação Brasileira das Empresas de Refeições Coletivas (ABERC, 2019):

No Brasil esse setor movimentou em torno de $\mathrm{R} \$ 50,7$ bilhões/ano, e atingiu o número de 20,9 milhões de refeições/dia no ano de 2018, sendo o quinto país do mundo no qual as pessoas realizam, pelo menos, uma refeição ao dia fora do lar (ABERC, 2019).

Durante o preparo de refeições em uma UAN ocorrem diversas etapas que envolvem desde a seleção e acondicionamento dos insumos, até a preparação do alimento final (OLIVEIRA; OLIVEIRA; PEREIRA, 2017). De acordo com a American Dietetic Association (ADA), trata-se de fases que envolvem um conjunto de ações em cadeia, relacionado ao processamento do alimento, em que vão ocorrer perdas/desperdícios, desde a colheita do insumo (perda de $20 \%$ ) até o processamento culinário e hábitos alimentares, sendo este I\% (STOCCO; MOLINA, 2020).

Nesse contexto, por ser responsável pela manipulação de grandes quantidades de alimentos a UAN precisa ser dotada de ferramentas que proporcionem melhoria e 
excelência constante, independente do contexto a qual esteja inserida, buscando uma padronização e qualidade e sua gestão gira em torno da a produção de comida e da prestação de serviços (ARANHA; GUSTAVO, 2018).

A partir disso, nota-se que devem ser aplicadas as recomendações destacadas na Resolução RDC no 216, de I5 de setembro de 2004, que estabeleceu procedimentos de Boas Práticas para Serviços de Alimentação (ANVISA, 2004). Essa Resolução garante além de qualidade sanitária do ambiente e da manipulação dos ambientes, sendo fundamental o conhecimento do processo produtivo para garantir o rigor das Boas Práticas (STOCCO; MOLINA, 2020).

O desperdício de alimentos está relacionado ao preparo de alimentos em UAN quando as sobras dos alimentos produzidos não são distribuídas, bem como quando os restos de

alimentos não consumidos são deixados nos pratos dos clientes. Além da quantidade de alimentos desperdiçados, é necessário considerar a utilização de outros recursos externos, como a utilização de mão de obra, o uso de saneantes, água e energia. Estes fatores vão variar de acordo com fatores como colaboradores e porções. Nesse sentido, destaca-se que as UAN's precisem estabelecer o nível de desperdício de alimentos entre o e Io\% (ZARO, 2018).

Neste contexto o nutricionista surge como profissional fundamental na adoção de ações educativas contínuas e bem estruturadas aos comensais para a melhoria dos hábitos alimentares. Este profissional atua para promover a atenção dos profissionais que atuam nas UANS com os alimentos dos clientes, assim como a realização de treinamentos periódicos aos funcionários daUAN, e elaboração de cardápios levando em consideração as características regionais eclimáticas são medidas que minimizam as perdas (PIEROTE et al., 2017).

O Serviço Social do Comércio (SESC), aponta que no Brasil, o desperdício de alimentosafeta em torno de 12 bilhões de reais a cada ano e que todos os dias chegam a ser descartados 39 milhões de toneladas de alimentos, quantitativo equivalente a alimentação de cerca de $78 \%$ dos 50 milhões de pessoas que ainda enfrentam a fome no país, nas refeições 
de café da manhã,almoço e jantar (OLIVEIRA; OLIVEIRA; PEREIRA, 20I8).

Diante desses dados, observa-se que sobras e restos de alimentos são as principais causas dos desperdícios, elevando os custos para a UAN, sendo assim, é fundamental a implementação de medidas corretivas e de controle que tenham como objetivo beneficiar não somente a empresa, mas também o consumidor final. $O$ nutricionista tem papel fundamental na prevenção de perdas em uma UAN em todas as etapas do processo, acompanhando lado a lado os demais funcionários, assim, o estudo justifica-se pela relevância profissional do nutricionista, demonstrando por meio dos artigos aqui apresentados como minimizar esses desperdícios e o seu impacto financeiro.

Diante do contexto, questiona-se "quais os fatores associados ao desperdício de alimentos em Unidades de Alimentação e Nutrição (UANs)?” Para tal, adotou-se como objetivo identificar os fatores associados ao desperdício de alimentos em Unidade de Alimentação Nutrição.

\section{MATERIAIS E MÉTODOS}

Trata-se de um estudo do tipo revisão integrativa da literatura. A revisão integrativa envolve uma análise de estudos passam a dar suporte para a tomada de decisão dos profissionais, promovendo uma melhor prática clínica, através da síntese da temática proposta.

Este método de pesquisa permite a síntese de múltiplos estudos publicados e possibilita conclusões gerais a respeito de uma particular área de estudo (MENDES; SILVEIRA; GALVÃO, 2008)

O levantamento bibliográfico foi realizado nas bibliotecas eletrônicas Scientific Eletronic Libray Online (SciELO) e Biblioteca Virtual em Saúde (BVS) com as seguintes basesde dados: Literatura Latino-americana e do Caribe em Ciências da Saúde (LILACS) e Medical Literature Analysis and Retrieval System Online (MEDLINE), disponibilizados diretamente por intermédio de pesquisa online.

Foram adotados como critérios de inclusão para o estudo artigos em português e 
inglês, selecionados por meio de buscas online, publicados nos últimos cinco anos (2017202I), bem como aqueles que que atenderam aos critérios de inclusão de acordo com o tema proposto à questão norteadora e aos objetivos desse estudo. E, foram excluídos artigos repetidos entre as bases, resenhas, anais de congressos, teses, capítulos de livros e resumos.

Visando assegurar as buscas, foi consultado o Descritor em Ciências da Saúde (DeCS). Os termos utilizados na busca serão: desperdício de alimentos, alimentação coletiva, aproveitamento integral dos alimentos e nutricionistas, por meio da utilização do operador booleano AND, publicados no período dos últimos cinco anos (2017-202I), no idioma português e inglês. Como forma complementar de busca bibliográfica, foi adotada a estratégia de comparar a bibliografia citada em cada artigo avaliado com a bibliografia obtida pelos meios supracitados.

Foram selecionadas para leitura na íntegra todas as publicações potencialmente elegíveis. Após a pré-seleção dos artigos, por meio da leitura flutuante dos resumos uma segunda análise foi realizada, através da leitura minuciosa das publicações pré-selecionadas para decidir inclusão e exclusão dessas produções, de acordo com critérios preestabelecidos. Nesta etapa, o trabalho foi revisado por um revisor independente, o orientador, que utilizou a técnica do consenso para seleção dos artigos a serem utilizados para pesquisa.

A presente pesquisa foi desenvolvida a partir de uma análise e leitura de artigos publicados por diversos autores com a finalidade de comparar os seus respectivos pontos de vista, reconhecendo os métodos por eles utilizados e discutidos a respeito do controle do desperdício de alimentos em UANs.

\section{RESULTADOS E DISCUSSÃO}

Feitas as associações dos descritores nas bases de dados, de 428 artigos que se correlacionava com os descritores informados pelas bases de dados, 332 estudos não respondiam à pergunta norteadora dessa pesquisa, assim, 96 estudos se relacionavam com a temática apenas, entretanto, 54 foram excluídos da amostra por não se adequarem ao período de publicação pré-estabelecido, assim, foram lidos os títulos e resumos de um número total de 
42 artigos. Após a leitura, mais 6 foram excluídos pois eram duplicados nas bases de dados e mais I2 por não possuírem texto completo.

Assim, 24 estudos foram lidos e 16 foram excluídos por não responder à questão norteadora, definindo assim a amostra final desta revisão, onde, acordo com a classificação, as pesquisas que compuseram a amostra da literatura e enquadram-se como artigos originais $(n=8)$, compondo assim os resultados e discussão do artigo apresentado, conforme disposto na figura I abaixo.

Figura r: Fluxograma do processo de seleção dos artigos.

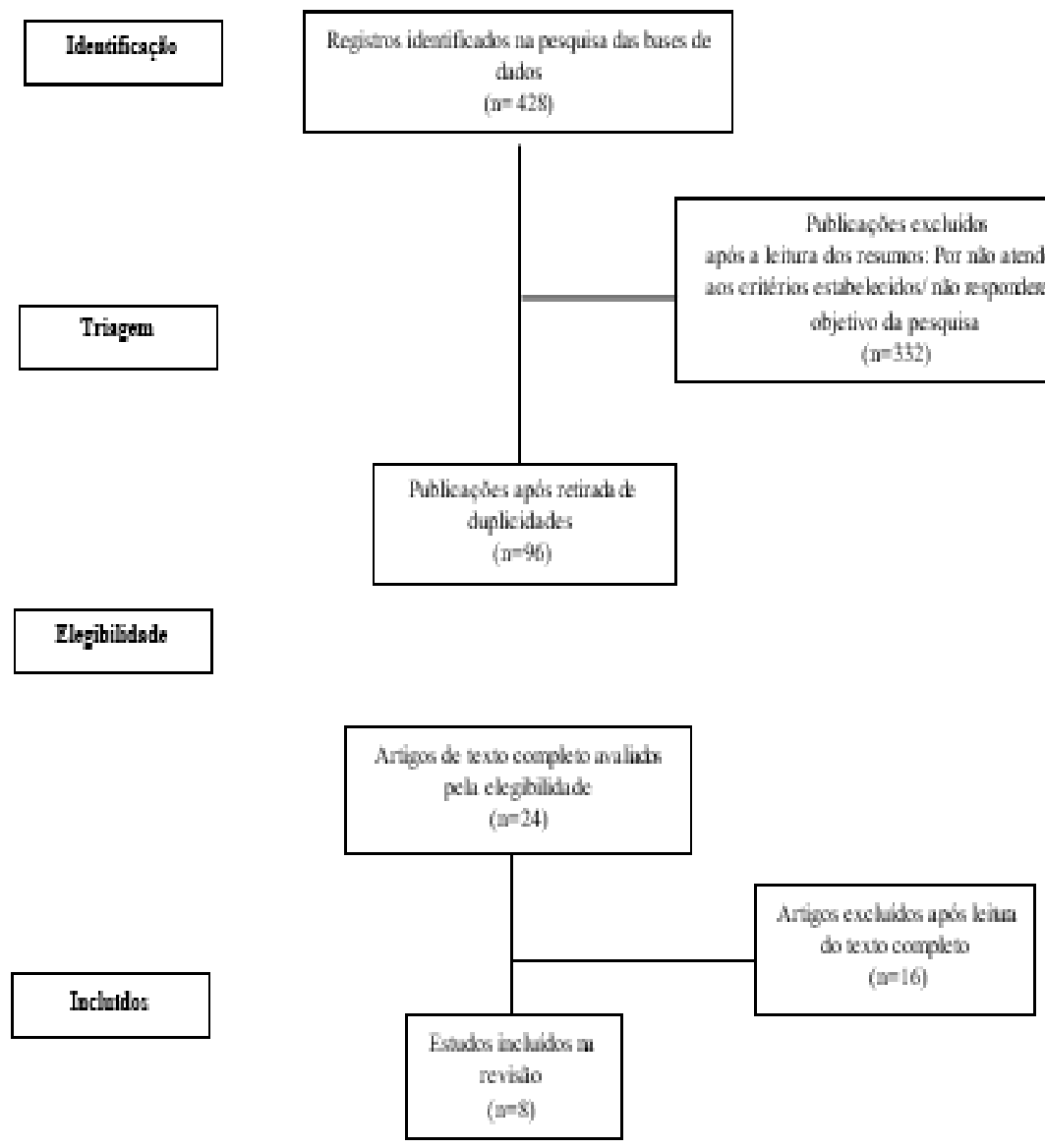

Posteriormente, foi realizada a caracterização dos artigos, como mostra o quadro I, referente ao ano e local de publicação dos artigos, desenho metodológico dos estudos, características da amostra, os principais resultados e considerações. 


\section{Quadro I - Caracterização da amostra (n=8).}

\begin{tabular}{|c|c|c|c|c|c|}
\hline Autor & Ano & Metodologia & $\begin{array}{l}\text { Características } \\
\text { da amostra }\end{array}$ & Resultados & Considerações \\
\hline Brito; Oliveira & 2017 & $\begin{array}{l}\text { Estudo } \\
\text { qualitativ } \\
\text { o } \\
\text { descritivo }\end{array}$ & $\begin{array}{l}\text { Avaliou o resto- } \\
\text { ingestão } \\
\text { a } \\
\text { almoço } \\
\text { servidoaos } \\
\text { comensais em } \\
\text { umerviço } \\
\text { dietética de um } \\
\text { hospital } \\
\text { localizado } \\
\text { no } \\
\text { município de } \\
\text { SãoJosé do Rio } \\
\text { Preto. }\end{array}$ & 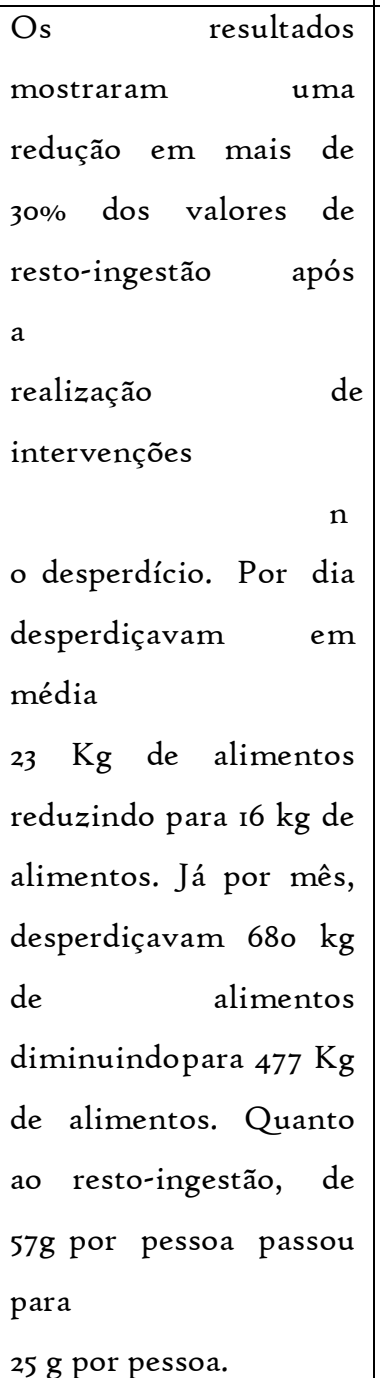 & $\begin{array}{l}\text { Campanhas } \\
\text { e conscientização e as } \\
\text { mudanças } \\
\text { o } \\
\text { porcionamento } \\
\text { trouxeram benefícios } \\
\text { aoserviço de nutrição e } \\
\text { dietética como a } \\
\text { reduçãodos custos, } \\
\text { gerando umaumento } \\
\text { na economiamensal. }\end{array}$ \\
\hline Furtado et al., & 2019 & $\begin{array}{l}\text { Estudo } \\
\text { dotipo } \\
\text { quantitativo, } \\
\text { de naturez } \\
\text { adescritiva } \\
\text { ede } \\
\text { corte } \\
\text { transversal }\end{array}$ & $\begin{array}{l}\text { Realizado em } \\
\text { duas } \\
\text { Ns inseridas no } \\
\text { Vale do Taquari, } \\
\text { RS }\end{array}$ & $\begin{array}{l}\text { Comparando as duas } \\
\text { UANs, nos três } \\
\text { períodos distintos, } \\
\text { verificou-se que na } \\
\text { UAN A também não } \\
\text { houve } \\
\text { significativa para o } \\
\text { desperdício } \\
\text { alimentos }(p=0,135) \text { e }\end{array}$ & $\begin{array}{l}\text { Na média geral do resto } \\
\text { ingesta per capita das } \\
\text { duas UANs e na UAN } \\
\text { B a campanha no } \\
\text { período durante foi } \\
\text { eficaz. }\end{array}$ \\
\hline
\end{tabular}




\begin{tabular}{|c|c|c|c|c|c|}
\hline & & & & $\begin{array}{l}\text { na UAN B, } \\
\text { apenas durante a } \\
\text { campanha, a redução do } \\
\text { resto ingesta per capita } \\
\text { foi } \\
\text { a }(\mathrm{p}=0,045), \quad \text { porém } \\
\text { antes } \mathrm{e} \quad \text { foram } \\
\text { após } \quad \text { não }\end{array}$ & \\
\hline & & & & $\begin{array}{l}\text { observadas diferenças } \\
\text { significativas. }\end{array}$ & \\
\hline Kuhn et al., & 2019 & $\begin{array}{l}\text { Estudo de } \\
\text { corte } \\
\text { transversale } \\
\text { modo de } \\
\text { abordagem } \\
\text { quantitativo }\end{array}$ & $\begin{array}{l}\text { Realizado em } \\
\text { uma UAN } \\
\text { inserida em uma } \\
\text { empresa } \\
\text { fabricante de } \\
\text { embalagens de } \\
\text { aço, localizada } \\
\text { em município do } \\
\text { Vale do Taquari, } \\
\text { Rio Grande do } \\
\text { Sul. }\end{array}$ & 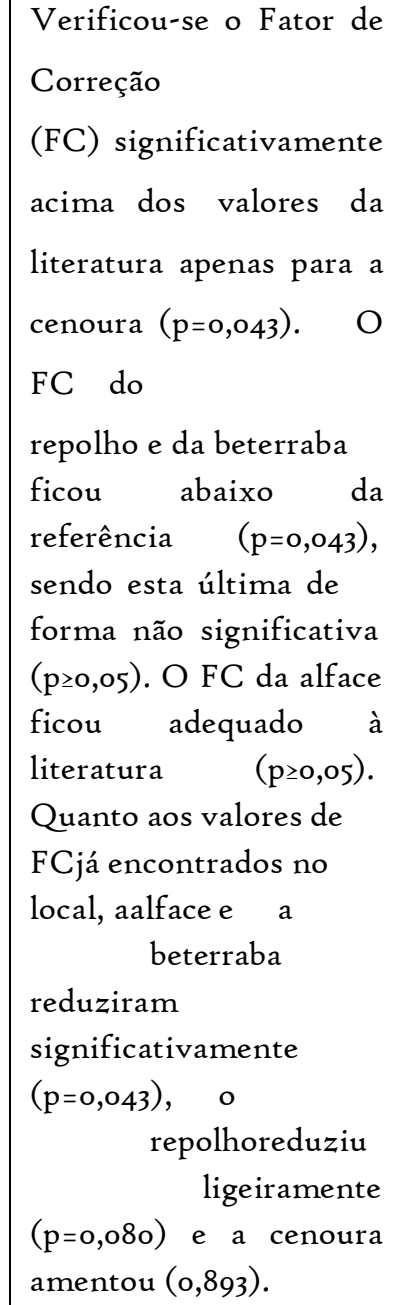 & $\begin{array}{l}\text { Conclui-se que não } \\
\text { houve } \\
\text { desperdí } \\
\text { cio expressivo dos } \\
\text { vegetais quando } \\
\text { comparados } \\
\text { valores de referência } \\
\text { da literatura, com } \\
\text { exceção da cenoura, e } \\
\text { que a UAN reduziu o } \\
\text { desperdício } \\
\text { maioria dos vegetais } \\
\text { avaliados. }\end{array}$ \\
\hline
\end{tabular}




\begin{tabular}{|c|c|c|c|c|c|}
\hline $\begin{array}{l}\text { Maffassiolli } \\
\text {;Koglin }\end{array}$ & 2020 & $\begin{array}{l}\text { Estudo } \\
\text { observaciona } \\
\text { ltransversal }\end{array}$ & $\begin{array}{l}\text { Desenvolvido na } \\
\text { unidade de } \\
\text { alimentação e } \\
\text { nutrição de um } \\
\text { hospital privado } \\
\text { da cidade de } \\
\text { Porto Alegre, } \\
\text { estado do Rio } \\
\text { Grande do Sul. }\end{array}$ & $\begin{array}{l}\text { O estudo mostrou que } \\
\text { 21,6\% dos colaboradores } \\
\text { afirmaram deixar restos } \\
\text { de comida no prato após } \\
\text { o almoço. Os principais } \\
\text { motivos para este } \\
\text { desperdício fora } \\
\text { m relacionados ao modo } \\
\text { de preparo dos } \\
\text { alimentos, incluindo o } \\
\text { tempero, temperatura } \\
\text { preparações no bufê, } \\
\text { fluxo do refeitório, onde } \\
\text { só é possível se } \\
\text { servir vez das } \\
\text { uma }\end{array}$ & $\begin{array}{l}\text { A realização de } \\
\text { campanhas } \\
\text { institucionais e a } \\
\text { apresentação mensal } \\
\text { de indicadores aos } \\
\text { comensais auxiliam } \\
\text { nabusca pela redução } \\
\text { da taxa de resto- } \\
\text { ingestão. }\end{array}$ \\
\hline & & & & $\begin{array}{l}\text { conscientização dos } \\
\text { comensais. }\end{array}$ & \\
\hline $\begin{array}{l}\text { Quemelli } \\
; \\
\text { Nogueira }\end{array}$ & 2020 & $\begin{array}{l}\text { Estudo } \\
\text { exploratório } \\
\text {,descritivo }\end{array}$ & $\begin{array}{l}\text { O refeitório onde } \\
\text { foi realizada a } \\
\text { pesquisa fica } \\
\text { dentro do } \\
\text { Hospital Estadual } \\
\text { Roberto Arnizaut } \\
\text { Silvares(HRAS), } \\
\text { localizado no } \\
\text { município de } \\
\text { São } \\
\text { Mateus-ES }\end{array}$ & $\begin{array}{l}\text { O resultado encontrado } \\
\text { no resto ingesta antes da } \\
\text { campanha era de } 7,15 \% \text {, } \\
\text { correspondente } \\
48,2 \mathrm{~g} / \text { servidor. }\end{array}$ & $\begin{array}{l}\text { Após a campanha } \\
\text { contra o desperdício, } \\
\text { o resto ingesta foi } \\
\text { reduzido para } 4,62 \% \text {, } \\
\text { o equivalente a } \\
28,6 \mathrm{~g} / \text { servidor, } \\
\text { redução demonstra os } \\
\text { efeitos positivos da } \\
\text { Campanha } \\
\text { Sensibilização. }\end{array}$ \\
\hline
\end{tabular}




\begin{tabular}{|c|c|c|c|c|c|}
\hline Ricarte et al., & 2021 & $\begin{array}{l}\text { Estudo } \\
\text { quantitativo } \\
\text { exploratório }\end{array}$ & $\begin{array}{l}\text { Realizado em } \\
\text { umRestaurante } \\
\text { Universitário, } \\
\text { emFortaleza-CE }\end{array}$ & 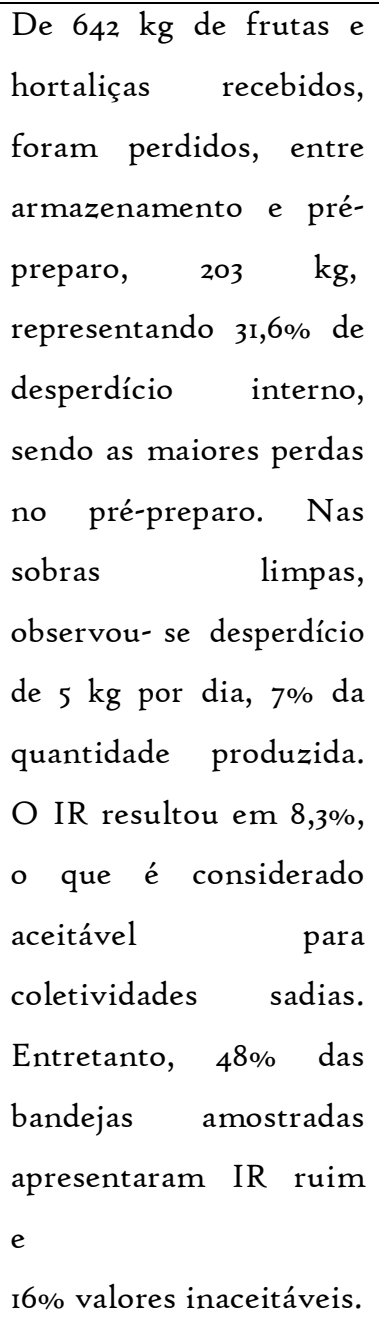 & 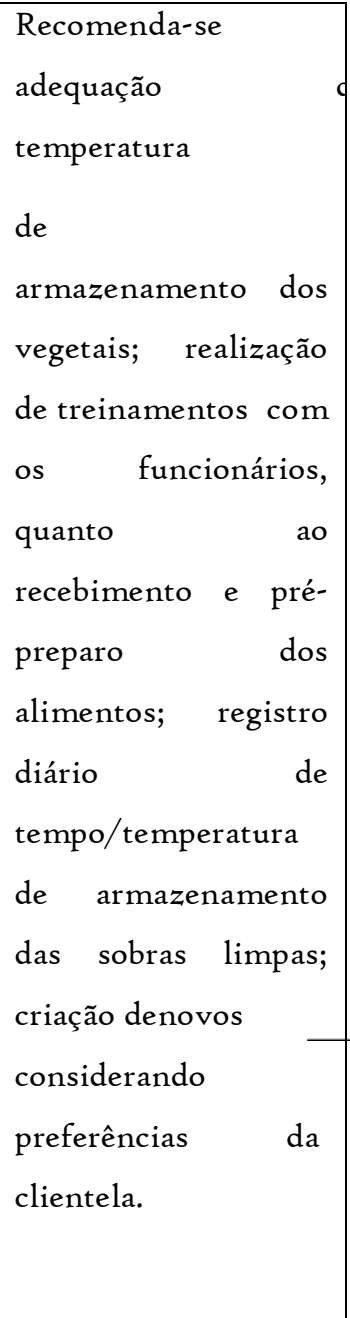 \\
\hline Soares et al., & 2018 & $\begin{array}{l}\text { Estudo } \\
\text { dotipo } \\
\text { transversal e } \\
\text { de } \\
\text { caráte } \\
\text { rquantitativo }\end{array}$ & $\begin{array}{l}\text { Realizado em } \\
\text { umrestaurante } \\
\text { universitário, que } \\
\text { atende alunos e } \\
\text { servidores de } \\
\text { umauniversidade } \\
\text { pública, } \\
\text { localizada na }\end{array}$ & $\begin{array}{l}\text { Os resultados } \\
\text { mostraram índice de } \\
\text { resto-ingestão de r6,76, } \\
\text { classificado como ruim. } \\
\text { Os per capitas da } \\
\text { refeição e do resto- } \\
\text { ingestão } \\
\text { mostraram } \\
\text { elevados, } \\
\text { sendo respectivamente }\end{array}$ & $\begin{array}{l}\text { O } \\
\text { ante Universitário } \\
\text { estudado apresentou } \\
\text { níveis } \\
\text { consideravelmente } \\
\text { altos de desperdício } \\
\text { em todos os dias } \\
\text { estudados, revelando } \\
\text { a necessidade } \\
\text { de intervenções } \\
\text { quanto }\end{array}$ \\
\hline
\end{tabular}




\begin{tabular}{|c|c|c|c|c|c|c|}
\hline & & & $\begin{array}{l}\text { cidade de Picos, } \\
\text { no estado do } \\
\text { Piauí. }\end{array}$ & $\begin{array}{l}\text { o,8i2kg e I67,6g. Em } \\
\text { média, II9,ookg de } \\
\text { alimentos } \\
\text { m desperdiçados todos } \\
\text { os dias, o que } \\
\text { alimentaria cerca de is6 } \\
\text { pessoas. }\end{array}$ & $\begin{array}{l}\text { ao planejamento da } \\
\text { distribuição de } \\
\text { realização de } \\
\text { atividades educativas } \\
\text { junto aos comensais } \\
\text { no dos } \\
\text { despertar do duanto } \\
\text { consciência } \\
\text { mesmos } \\
\text { sua de } \\
\text { responsabilidade } \\
\text { diante } \\
\text { alimentos. }\end{array}$ & \\
\hline Stocco; Molina & 2020 & $\begin{array}{l}\text { Estudo } \\
\text { quantitativo, } \\
\text { descritivo e } \\
\text { exploratório }\end{array}$ & $\begin{array}{l}\text { Desenvolvido em } \\
\text { uma localizada } \\
\mathrm{N} \text { na de } \\
\text { cidade Louveira-SP }\end{array}$ & $\begin{array}{l}\text { Observou-se que a } \\
\text { média do resto-ingestão } \\
\text { per capita passou de } 58 \mathrm{~g}, \\
\text { antes da campanha, para } \\
\text { 38,9g, após a finalização } \\
\text { da campanha, o que } \\
\text { indica uma redução de } \\
\text { 33\% no desperdício de } \\
\text { alimentos } \\
\text { comensais. }\end{array}$ & $\begin{array}{l}\text { A educação } \\
\text { nutricional realizada } \\
\text { com os comensais } \\
\text { por meio da } \\
\text { campanha } \\
\text { conscientização teve } \\
\text { influência } \\
\text { diminuição de resto- } \\
\text { ingestão per capita. }\end{array}$ & 1993 \\
\hline
\end{tabular}

\section{Desperdício de alimentos}

De acordo com o estudo de Soares et al., (2018) o desperdício de alimentos se apresentacomo sendo um problema em todo o mundo e o Brasil se classifica como um dos dez países que mais promovem o desperdício. Aponta-se para cerca de quatro bilhões de toneladas desperdiçadas por ano, o que representa cerca de $30 \%$ do total produzido a cada ano. Nesse contexto, o desperdício, se mostra como um problema que afeta a economia do 
país e repercutede modo negativo na sociedade.

Brito e Oliveira, (2017) mostra que nos serviços institucionais de alimentação ocorrem perdas de $24 \%$ nas escolas; $47 \%$ nos hospitais; $40 \%$ nas instituições militares; $25 \%$ nos restaurantes de funcionários e $34 \%$ nos restaurantes e cerca de $30 \%$ desse desperdício são originados dos pratos dos usuários; 60\% na preparação e $5 \%$ das perdas (deterioração).

De acordo com Quemelli e Nogueira, (2020) desperdiçar alimentos é como sumir com um material que poderia ser aproveitado, em virtude da quantidade de alimentos que são desprezados todos os dias ser capaz de alimentar cerca de io milhões de pessoas. Com isso, desperdício de alimentos gera prejuízos e está diretamente relacionado ao processo produtivo das refeições, tendo como principais fatores o planejamento inadequado, as preferências e aversões alimentares, o treinamento de funcionários, além do porcionamento dos alimentos.

Stocco; Molina, (2020) aponta que durante o processo de pré-preparo e produção de alimentos, é importante evitar que ocorram sobras e essa prevenção se faz a partir do monitoramento de toda ação, aplicando-se as Boas Práticas de Fabricação (BPF), desde a recepção dos insumos até o preparo. Além disso, Furtado et al., (2019) destaca que o armazenamento de mercadorias é uma das fases que merece fundamental atenção, em virtude da importância do controle de qualidade em uma UAN, uma vez que o material armazenado corretamente promove a redução de perdas e contaminações.

Kuhn et al., (2019) destaca que registrar a quantidade desprezada é muito importanteem uma UAN, uma vez que esses dados podem ser utilizados para implementarem estratégiasde racionar, visando minimizar os desperdícios e otimizar a produtividade. Além disso, osregistros fornecem informações acerca da quantidade de alimentos perdidos, sendo utilizadosno cálculo dessas perdas, bem como mensurar os custos e diagnosticar as causas do desperdício.Maffassiolli; Koglin, (2020) destaca que o gerenciamento e controle do desperdício de alimentos em uma UAN, é fundamental para identificar o acúmulo de restos e sobras,acarretando em repercussões ética e econômica, bem como política, social e ambiental. Ricarteet al., (202I) aponta assim, que o desperdício envolve os alimentos que não foram utilizados;preparações prontas não distribuídas; alimentos que sobram nos pratos dos clientes, 
denominado resto ingesta.

No sistema de distribuição self-service livre, percebe-se com maior clareza a quantidadede desperdício. Este tipo de serviço induz as pessoas a se servirem mais do que realmente necessitam, paga-se um valor fixo e se come à vontade, podendo os restos de alimentos chegar a $71 \%$ acima do esperado, o que difere dos restaurantes comerciais cuja modalidade é self- service por peso $(\mathrm{Kg})$, onde todo alimento é pesado antes de ser consumido e os clientes pagam pela quantidade de alimento servido. Desta forma modalidades de self-service por peso $(\mathrm{Kg})$ auxiliam na redução do desperdício, já que os clientes pagam pelo que consomem (MAFFASSIOLLI; KOGLIN, 2020).

É importante que se observe, controle e mantenha as condições aceitáveis para o controle de temperatura, higienização, rotatividade de estoque, ventilação e armazenamento adequado, para que haja redução nos custos de produção (FURTADO et al., 2019). Nesse contexto, o estudo de Soares et al., (2018) aponta que para avaliar o índice de desperdício emUAN, dentro do custo mensal, é verificado o percentual aceitável de sobras, conforme expostono quadro 2, que aponta para a classificação das sobras.

Quadro 2- Classificação das sobras.

\begin{tabular}{|c|c|}
\hline Percentual & Classificação desempenho do serviço \\
\hline $5 \%$ & Ótimo \\
\hline $5 \%$ e $10 \%$ & Bom \\
\hline $10 \%$ e $15 \%$ & Regular \\
\hline$>15 \%$ & Péssim \\
& 0 \\
\hline
\end{tabular}

Fonte: Soares et al., (2018).

I. Resto ingesta

Resto ingesta é um critério para avaliar a quantidade de alimentos que sobram dos pratosdos comensais, sobre a quantidade de alimentos que foram distribuídos, ou seja, é todo alimentoque foi devolvido no prato ou bandeja pelo cliente, sendo um dos fatores que mais contribui para elevação dos custos e desperdício em uma UAN, porque, quanto maior o índice, maior é a insatisfação dos comensais. Diante deste exposto, surge a necessidade de aplicar técnicas que contribuam para redução do desperdício e melhorem a utilização dos 
alimentos (BRITO; OLIVEIRA, 2017)

De acordo com o estudo de Quemelli; Nogueira, (2020, p. 39) o índice do resto ingestaestá diretamente relacionado ao planejamento inadequado do número de refeições confeccionadas, além de:

A frequência diária dos comensais treinamento e capacitação dos manipuladores de alimentos à produção; utensílios utilizados inadequadamente; preparações contrárias aos hábitos alimentares dos comensais, além da eficácia na produção e apresentação dos alimentos, observando-se a má aparência das preparações.

Stocco; Molina, (2020, p. 39) aponta ainda que:

O resto ingesta é um dos fatores que leva ao aumento dos custos e desperdício, expressando a insatisfação e/ ou hábitos errôneos dos comensais, ocorre a necessidade de avaliar este índice para propor medidas corretivas que beneficiem as empresas e consumidores. A classificação do resto ingesta é realizada de acordo com o percentualencontrado ao mensurar as provenientes de pratos e bandejas dos comensais. Utiliza-se de 5 a 10\% - "Bom", de 10 a 15\%- "Regular" e acima de $15 \%$ "Ruim".

\section{Sobras}

Brito; Oliveira, (2017) aponta que sobras são os alimentos produzidos que não foram

distribuídos, sendo, que o resto ingesta é a quantidade de alimentos devolvida no prato ou na bandeja pelo cliente. As sobras podem ser divididas em aproveitável e não aproveitável, onde a primeira é o alimento produzido que não foi para a distribuição, podendo este ser reaproveitado em outra refeição e a sobra não aproveitável, a sobra suja que é o alimento produzido e distribuído que não foi consumido, sendo descartado pelo serviço (FURTADO et al., 2019).

De acordo com Maffassiolli; Koglin, (2020) para auxiliar no controle de sobras, a UAN deve realizar o acompanhamento de toda a distribuição dos alimentos, bem como promover treinamentos e conscientizar a equipe, visando definir metas quanto ao controle das sobras, além de elaborar cardápios que satisfaçam os comensais, onde, por conseguinte, seja possível otimizar a produção de sobras. Furtado et al., (2019) aponta que "quando houver percentual deresto ingesta, com valores entre 2 e $5 \%$ da quantidade servida ou de is a $45 \mathrm{~g}$ por cliente e percentuais de sobras aceitáveis de $3 \%$ ou de 7 a $25 \mathrm{~g}$ por cliente, ou ainda valores baseados nopróprio estabelecimento."

Furtado et al., (2019) aponta ainda que as sobras precisam ser avaliadas não somente 
noque diz respeito a questão econômica da UAN, mas também, sobre a falta de integração com ocliente.

O estudo de Ricarte et al., (202I) realizado em uma UAN, apontou que de $642 \mathrm{~kg}$ de frutas e hortaliças recebidos, as sobras representaram cerca de 31,6\%, durante a fase de armazenamento e pré-preparo, entretanto, as maiores sobras foram observadas na fase de pré- preparo. O estudo revelou ainda que quanto as sobras limpas, verificou-se um desperdício querepresentou cerca de $5 \mathrm{~kg} / \mathrm{dia}$, o que apontou para cerca de $7 \%$ da produção.

Quemelli; Nogueira, (2020) em seu estudo, aponta que quando os resultados das sobras representam a partir de 10\%, a falha encontra-se nos cardápios, que se mostram como inadequados, apontando assim para o mal planejamento ou mal execução.

\section{CONCLUSÃO}

Frente ao exposto, observa-se que os responsáveis pela UAN devem implantar medidaseducativas aos comensais assim como para os funcionários, aonde é fundamental que haja a aplicação de treinamentos para que os mesmos estejam aptos a utilizar os utensílios adequados e treinados para distribuição e padronizando a porção dos alimentos, o que promove a reduçãodo desperdício.

Observa-se que os fatores associados ao desperdício de alimentos em UANs são: a forma de manipulação; a apresentação dos alimentos; a limpeza do ambiente; a quantidade de alimentos em que são servidos quando a la carte; a quantidade de alimentos manipulados por dia; o sabor dos alimentos; e os atores sensoriais, aparência, aroma.

Assim, ao se considerar o Brasil é um país onde a subnutrição se caracteriza como sendo um problema de saúde pública, torna-se fundamental promover o controle do desperdício na UAN, em virtude da redução da perda de alimentos ser uma das maneiras indiretas de reduzir a fome, além disso, o nutricionista tem como papel social, a intervenção e educação nos locaisde atuação.

\section{REFERÊNCIAS}

ARANHA, FQ; GUSTAVO, AFS. Avaliação do desperdício de alimentos em uma unidade dealimentação e nutrição na cidade de Botucatu, SP. Higiene Alimentar, v. 32, n. 
$276 / 277,2018$.

BORGES, MP et al. Impacto de uma campanha para redução de desperdício de alimentos emum restaurante universitário. Engenharia Sanitária e Ambiental, v. 24, p. 843-848, 2019.

FURTADO, CR et al. Avaliação do resto ingesta durante campanha contra o desperdício de alimentos em duas Unidades de Alimentação e Nutrição do Vale do Taquari-RS. South American Journal of Basic Education, Technical and Technological, v. 6, n. I, 2019.

KUHN, GD et al. Avaliação do desperdício de alimentos durante o pré-preparo de vegetais em uma unidade de alimentação e nutrição. Disciplinarum Scientia e Saúde, v. 20, n. I, p.95-107, 2019.

MAFFASSIOLli, V; KOGLIN, G. Desperdício de Alimentos no Refeitório de um Hospital Privado no Sul do Brasil. Saúde e Desenvolvimento Humano, v. 8, n. 2, p. 6772, 2020.

OLIVEIRA, DA; OLIVEIRA, JL; PEREIRA, KN. Análise dos principais fatores de desperdício em uma Unidade de Alimentação e Nutrição-UAN. South American Journal ofBasic Education, Technical and Technological, v. 4, n. 2, 2017.

PARADA, AD; OLIVEIRA, FRG. Desperdício alimentar: conscientização dos comensais de um serviço hospitalar de alimentação e nutrição. Arquivos de ciências da saúde, v. 24, n. 3,p. 6I-64, 2017.

PIEROTE, NRA et al. Controle de Desperdício em Unidade de Alimentação e Nutrição emTeresina-PI. Revista Interdisciplinar, v. Io, n. 2, p. 58-64, 2017.

QUEMELLI, CA; NOGUEIRA, GB. Avaliação da sobra e do resto ingesta como estratégia naredução do desperdício de alimentos. Saber Científico, v. 9, n. 2, p. 30-42, 2021. 
RICARTE, MPR et al. Avaliação do desperdício de alimentos em uma unidade de alimentação e nutrição institucional em Fortaleza-CE. Saber Científico, v. I, n. I, p. I58-175, 2021.

SOARES, TC et al. Avaliação do desperdício de alimentos servidos no horário do almoço emRestaurante Universitário no estado do Piauí, Brasil. Revista Brasileira de Higiene e Sanidade Animal, v. 12, n. 3, p. 271-279, 2018.

STOCCO, AB. Avaliação do Resto-Ingestão Antes, Durante e Após uma Campanha de Conscientização Contra o Desperdício em uma Unidade de Alimentação e Nutrição. RevistaMultidisciplinar da Saúde, v. 2, n. I, p. 39-52, 2020.

VIANA, RM; FERREIRA, LC. Avaliação do desperdício de alimentos em unidade de alimentação e nutrição cidade de Januária, MG. Higiene Alimentar, v. 3I, n. 266/267, p. 22-26, 2017 .

ZARO, M. Desperdício de alimentos: velhos hábitos, novos desafios. Caxias do Sul, RS: Educs, v. 417, 2018. 